Document downloaded from:

http://hdl.handle.net/10251/51302

This paper must be cited as:

Sastre Calabuig, F.; Corma Canós, A.; García Gómez, H. (2012). Deep UV photocatlytic activation of ethane on silica surfaces. Applied Catalysis B: Environmental. 128:84-90. doi:10.1016/j.apcatb.2012.09.046.

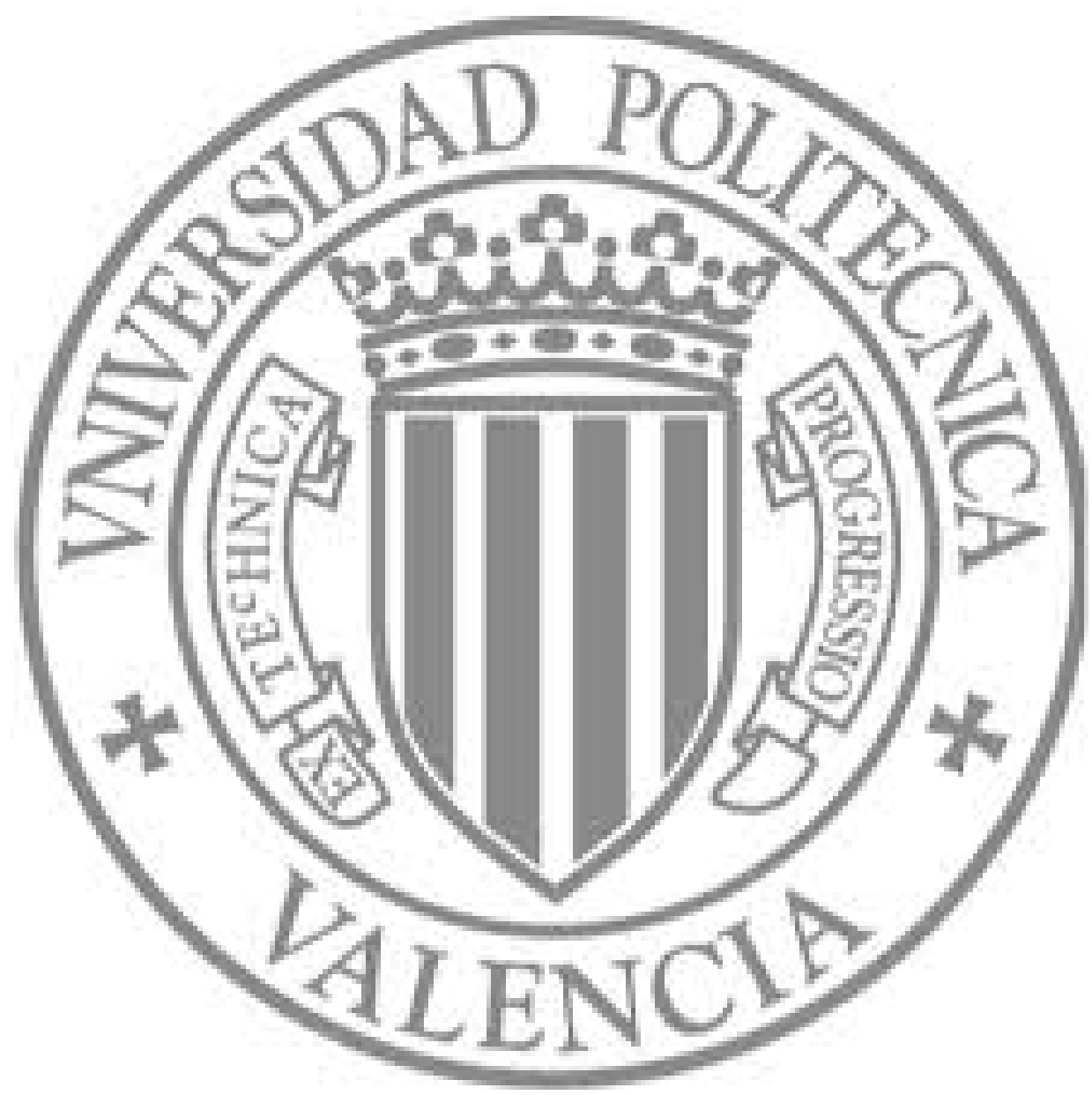

The final publication is available at

http://dx.doi.org/10.1016/j.apcatb.2012.09.046

Copyright Elsevier 


\title{
Deep UV photocatalytic activation of ethane on silica surfaces. ${ }^{1}$
}

\author{
Francesc Sastre, Avelino Corma* and Hermenegildo García*
}

Instituto Universitario de Tecnología Química CSIC-UPV, Universidad Politécnica de Valencia, Av. De los Naranjos s/n, 46022 Valencia, Spain.

Corresponding authors: acorma@itq.upv.es and hgarcia@qim.upv.es

\section{Abstract.}

Deep UV photolysis (165 or $185 \mathrm{~nm}$ ) of surface silanol groups leads to the homolytic $\mathrm{O}-\mathrm{H}$ bond breaking, generating silyloxyl radicals and hydrogen atoms. Silyloxyl radicals are able to activate ethane through hydrogen abstraction, whereby ethyl radicals are formed. Coupling of these ethyl radicals with silyloxyl radicals forms surface bound ethoxysilane that eventually will form ethanol. The product distribution of this radical process depends on the absence or presence of oxygen and may lead to the formation of ethanol together with light alkanes (methane, propane, butane and hexane) accompanied by C2 (acetaldehyde and acetic acid) and C1 (methanol, formaldehyde and formic acid) oxygenates. The presence of oxygen enhances ethane conversion and quenches the formation of alkanes by trapping alkyl radicals. It was found that micro and mesoporous silicas behave qualitatively similar with some differences in the product distribution. The most efficient material (higher conversion and higher percentage of products in the solid) was found to be Al-MCM 41. The energy consumption estimated based on a conversion of $6 \%$ on commercial beta zeolite was

\footnotetext{
${ }^{11}$ Dedicated to Prof. Jean-Marie Herrmann on occasion of his retirement
} 
$2.0 \mathrm{Gcal}$ per mol of ethane converted that is about 3.6 times smaller than the energy consumed form methane activation through an analogous process.

\section{Introduction.}

Low temperature activation of methane and ethane still constitutes a challenge for the chemistry of the XXI st Century due to the low reactivity of these two alkanes ${ }^{1-5}$. In addition, selective conversion of methane and ethane to liquid derivatives is a matter of large economical impact, since these two alkanes are the major constituents of natural gas and very frequently gas fields are in remote geographical areas. Technologically simple processes for the conversion of these two alkanes into liquids would be of interest. This will simplify transportation of natural gas to the consumers minimizing risks and reducing costs.

Different strategies including oxidative coupling aromatization ${ }^{6-8}$, aromatization ${ }^{9-12}$ and direct alcohol conversion ${ }^{13-15}$ have been tested for the low temperature selective alkane conversion, but most of the present processes suffer from severe catalyst deactivation and high energy consumption.

Recently we have reported that methane can be converted into methanol with a selectivity higher than $95 \%$ at methane conversion over $13 \%$ consuming in the order of $7.2 \mathrm{Gcal} \mathrm{mol}^{-1} 16,17$. The process consists in the photochemical irradiation of surface hydroxyl groups with deep UV $(\lambda<200 \mathrm{~nm})$ light. In this process oxyl radicals are generated on the solid surface by homolytic cleavage of $\mathrm{O}-\mathrm{H}$ bonds and these oxyl radicals are able to abstract one hydrogen from methane to generate methyl radicals 
16,17 . In the presence of oxygen these methyl radicals are trapped and converted into methyl peroxyl radicals that eventually form methanol and other oxidizing species. Selectivity in the process arises from the use of a high surface area microporous solid, such as zeolites that, on one hand provides, a high population of hydroxyl groups constrained in a reaction cavity, disfavouring other radical coupling steps and favouring the surface and oxygen trapping of the primary methyl radicals. Scheme 1 summarizes the process postulated for the low temperature activation of ethane by deep UV irradiation of solid surfaces, based on an analogous Scheme proposed for methane.

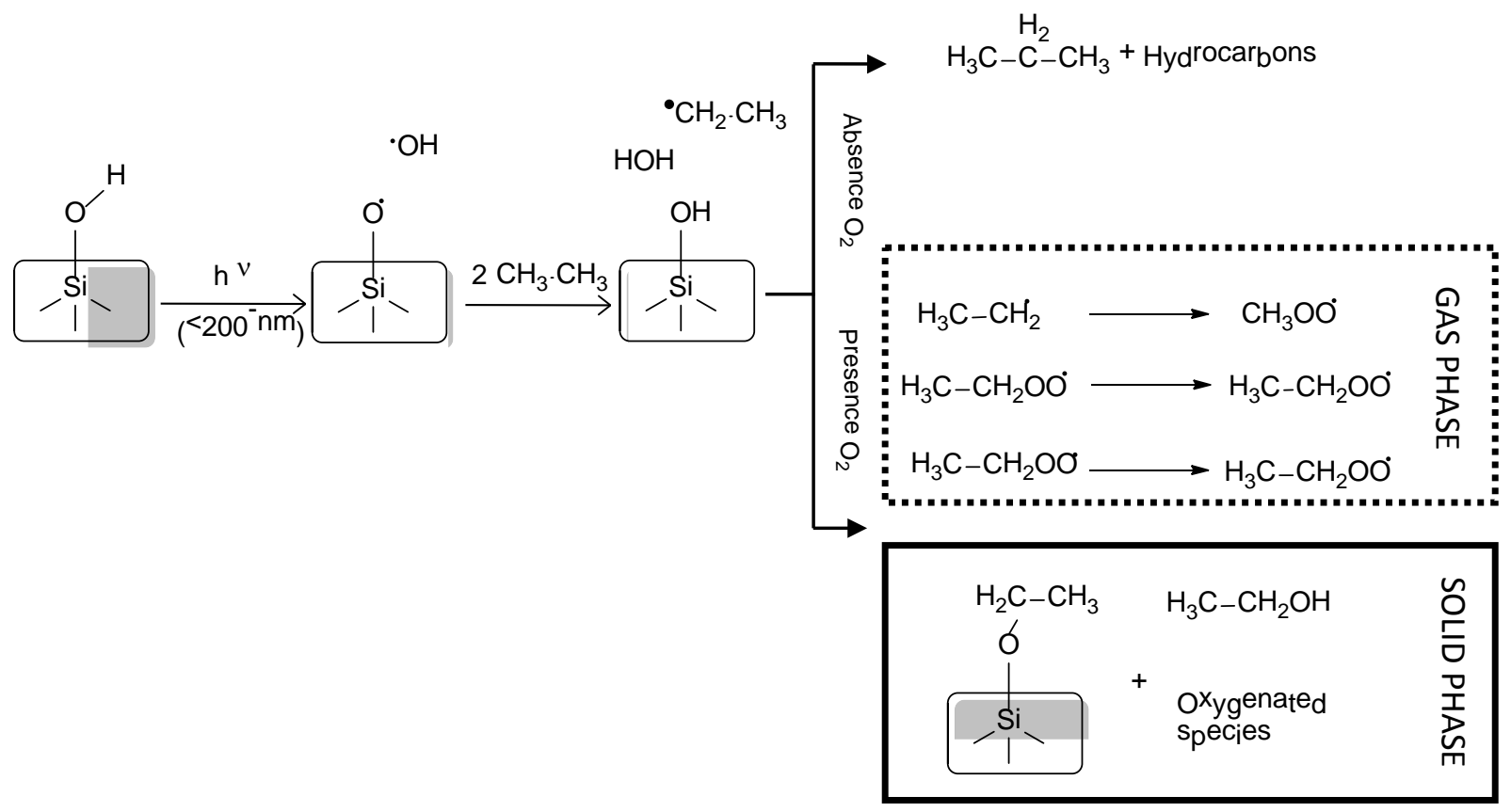

Scheme 1. Proposed mechanism for the deep UV transformation of ethane on silica surfaces. 
Continuing with this methodology consisting in the room-temperature photocatalytic activation of light alkanes and in order to expand the scope of the deep UV photolysis of solids for alkane activation, in the present paper we report on the conversion of ethane into ethanol, light alkanes and C2 and C1 oxygenates by deep UV irradiation of solids in contact with an atmosphere in which ethane o mixtures of ethane and oxygen are present.

\section{Results and Discussion.}

Considering the availability of deuterium (165 nm) and mercury (185 nm) lamps, preliminary experiments were carried out comparing the performance of these two radiation sources for ethane activation. Upon deep UV photolysis in the presence of silica surfaces, ethane was converted to mixtures of ethanol light alkanes (when oxygen was absent) and C1 plus C2 oxygenates (when oxygen was present) with similar product distribution for both lamps. However, due to the difference in power, wavelength and spectral energy emission the efficiency of the process in terms of ethane conversion and energy consumption was different depending on the irradiation lamp. This preliminary study using commercial Beta zeolite (Si/Al 11) as photocatalyst established that the mercury lamp was the most efficient light source and further studies were conducted mostly with this lamp.

Taking into account the nature of the system in where two phases (gas and solid) are present, mass balance and determination of the product distribution require analysis of both the gas phase and the solid. Gas phase analyses were performed by gas chromatography, while the study of the product distribution on the solid was 
carried out initially using doubly ${ }^{13} \mathrm{C}$-labeled ethane and the composition of the organic matter determined by solid state ${ }^{13} \mathrm{C}$ NMR spectroscopy. Remarkable differences depending whether oxygen was present or absent in the mixture were observed. The results obtained using commercial Beta zeolite are summarized in Tables 1 and 2 where the total ethane conversion, the percentage of it that remains adsorbed on the solid phase after the reaction and the main reaction products in the gas phase are indicated for both 165 and $185 \mathrm{~nm}$ irradiation.

Table 1. Activity data and product distribution observed for the room-temperature, deep UV photolysis of ethane on commercial Beta zeolite in the absence of oxygen. The initial composition of the gas phase was 82 and $18 \%$ of nitrogen and ethane, respectively.

\begin{tabular}{|c|c|c|c|c|c|c|c|c|c|c|c|}
\hline \multirow[b]{2}{*}{ Time (h) } & \multicolumn{5}{|c|}{$165 \mathrm{~nm}$} & \multicolumn{6}{|c|}{$185 \mathrm{~nm}$} \\
\hline & 0.08 & 0.5 & 1 & 5 & 14 & 0.08 & 0.5 & 1 & 2.5 & 5 & 14 \\
\hline Total conversion $(\%)^{a}$ & 0.5 & 0.6 & 3.2 & 3.3 & 7.5 & 1 & 3.9 & 4.5 & 7.2 & 10.2 & 28.4 \\
\hline \multirow[t]{2}{*}{$\begin{array}{l}\text { Percentage of the total } \\
\text { conversion on the solid }\end{array}$} & 99.6 & 96.0 & 98.9 & 95.8 & 97.1 & 99.1 & 99.4 & 95.6 & 96.6 & 96.5 & 96.7 \\
\hline & \multicolumn{11}{|c|}{ Products observed in the gas phase (\%) } \\
\hline $\mathrm{H}_{2}$ & 100 & 82.7 & 53.8 & 63.1 & 61.6 & 54.3 & 56.6 & 39.5 & 65.6 & 66.2 & 83.2 \\
\hline $\mathrm{CO}_{2}$ & $--^{c}$ & 17.3 & 39.5 & 11.1 & 6.8 & 45.7 & 43.4 & 7.3 & 6.2 & 10.2 & 1.5 \\
\hline $\mathrm{CO}$ & $--^{c}$ & $--^{c}$ & $--^{c}$ & $--^{c}$ & $--^{c}$ & $--^{c}$ & $--^{c}$ & $--^{c}$ & $--^{c}$ & 3.1 & 2.0 \\
\hline Methane & $--^{c}$ & $--^{c}$ & $--^{c}$ & 18.2 & 13.8 & $--^{c}$ & $--^{c}$ & $--^{c}$ & $--^{c}$ & $--^{c}$ & 4.3 \\
\hline Propane & $--^{c}$ & $--^{c}$ & 6.7 & 7.4 & 6.5 & $--^{c}$ & $--^{c}$ & 23.7 & 3.4 & 2.7 & 1.9 \\
\hline Butane & $--^{c}$ & $--^{c}$ & $--^{c}$ & 1.3 & 11.3 & $--^{c}$ & $--^{c}$ & 6.5 & 24.8 & 17.8 & 7.1 \\
\hline
\end{tabular}

a) Percentage of the initial moles of ethane that have disappeared at the indicated time. Mass balances over $95 \%$

b) Corresponding to a minor percentage respect to the total conversion, since almost all the converted ethane remains adsorbed onto the solid

c) Below detection limit 
Table 2. Activity data and product distribution observed for the room-temperature deep UV photolysis of ethane on commercial Beta zeolite in the presence of oxygen. The initial composition of the gas phase was 70,18 and $12 \%$ of nitrogen, ethane and oxygen, respectively.

\begin{tabular}{|c|c|c|c|c|c|c|c|c|c|c|c|}
\hline & \multicolumn{5}{|c|}{$165 \mathrm{~nm}$} & \multicolumn{6}{|c|}{$185 \mathrm{~nm}$} \\
\hline Time (h) & 0.08 & 0.5 & 1 & 2.5 & 14 & 0.08 & 0.5 & 1 & 2.5 & 14 & $14^{d}$ \\
\hline Total conversion $^{a}$ & 2.1 & 3.5 & & 9.8 & 17.68 & 6.0 & 13.4 & 13.9 & 16.6 & 45.1 & 3.7 \\
\hline $\begin{array}{l}\text { Percentage of the total } \\
\text { conversion on the solid }\end{array}$ & 99.9 & 99.6 & & 99.8 & 95.2 & 99.4 & 97.8 & 97.1 & 93.4 & 92.1 & 0 \\
\hline & \multicolumn{11}{|c|}{ Products observed in the gas phase ${ }^{b}$} \\
\hline $\mathrm{H}_{2}$ & 61.0 & 58.4 & & 58.6 & 31.2 & 50.8 & 14.4 & 10.4 & 22.9 & 42.8 & 35.8 \\
\hline $\mathrm{CO}_{2}$ & 39.0 & 41.6 & & 41.4 & 40.5 & 13.8 & 36.3 & 83.5 & 61.6 & 48.0 & 56.8 \\
\hline $\mathrm{CO}$ & $--^{c}$ & $--^{c}$ & & $--^{c}$ & 16.1 & $--^{c}$ & $--^{c}$ & $--^{c}$ & 11.1 & 5.4 & 3.9 \\
\hline Methane & $--^{c}$ & $--^{c}$ & & $--^{c}$ & 8.2 & $--^{c}$ & 11.5 & 5.2 & 3.9 & 3.5 & 3.0 \\
\hline Propane & $--^{c}$ & $--^{c}$ & & $--^{c}$ & 2.1 & 19.8 & 24.0 & 0.9 & 0.5 & 0.3 & 0.3 \\
\hline Butane & $--^{c}$ & $--^{c}$ & & $--^{c}$ & 1.9 & 15.6 & 13.8 & $--^{c}$ & $--^{c}$ & $--^{c}$ & $--^{c}$ \\
\hline
\end{tabular}

a) Percentage of the initial moles of ethane that have disappeared at the indicated time. Mass balances over $95 \%$

b) Corresponding to a minor percentage respect to the total conversion, since almost all the converted ethane remains adsorbed onto the solid Below detection limit.

c) No catalyst

As it can been seen in these Tables, conversions above $40 \%$ of the ethane present in the experiment were achieved in the presence of oxygen. Compared to similar experiments performed with methane, higher conversions are achieved in the case of ethane, this being in good agreement with the expected relative reactivity of both alkanes and with the corresponding $\mathrm{C}-\mathrm{H}$ bond energy ${ }^{18}$. What is remarkable in Tables 1 and 2 is that over $90 \%$ of the product distribution remains adsorbed on the Beta zeolite, the percentage of converted ethane in the gas phase being notably small 
(frequently a percentage lower than $1 \%$ of ethane conversion). In any case, particularly from the mechanistic point of view, it is remarkable, that the gas phase contains a high percentage of hydrogen than is higher at short irradiation times and decreases along the irradiation time due to the appearance of other compounds in the gas phase. Formation of hydrogen, is also observed when the commercial Beta zeolite is irradiated under $\mathrm{N}_{2}$ atmosphere and provides firm support to our assumption that deep UV photolysis of the solid promotes the homolytic $\mathrm{O}-\mathrm{H}$ bond cleavage forming hydrogen atoms (Eq. 1) that will be converted to dihydrogen (Eq 2). Over the course of the photolysis, hydrogen is accompanied by butane and methane. Butane will be formed by coupling of two ethyl radicals as indicated in the Eq. 6. Interestingly the methane will probably arise from the homolytic C-C bond cleavage (Eq. 4) followed by hydrogen abstraction. A blank control (see Table 2 most right column and corresponding footnote " $d$ ") shows that conversion of ethane by direct deep UV photolysis in the absence of solid is not zero, but one order of magnitude smaller than in the presence of zeolite. The poor result of the direct photolysis of ethane in the absence of solid is understandable considering that ethane does not almost absorb photons of $185 \mathrm{~nm}$ and that the cross section of the $\mathrm{O}-\mathrm{H}$ chromophore for this wavelength is much higher than that of ethane. We also made blank controls in which the system comprising the zeolite Beta and ethane were submitted to $254 \mathrm{~nm}$ photolysis in the presence or absence of oxygen. It should be noted that the deep UV $\mathrm{Hg}$ lamp has a twice stronger emission at $254 \mathrm{~nm}$, besides $185 \mathrm{~nm}$. The experimental results showed an ethane conversion at $15 \mathrm{~h}$ of 0.2 and $0.8 \%$ in the absence and presence of oxygen, respectively. These conversions are about two orders of magnitude lower than those achieved with deep UV. 


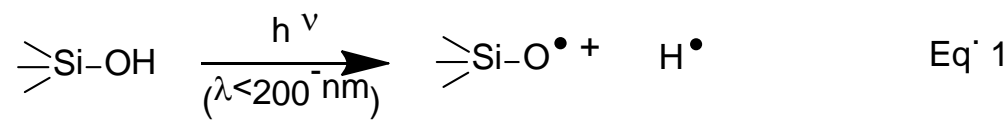

$$
\begin{aligned}
& 2 \mathrm{H}^{\bullet} \longrightarrow \mathrm{H}_{-} \mathrm{H} \longrightarrow q^{\cdot} 2
\end{aligned}
$$

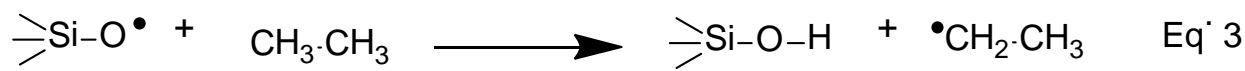

$$
\begin{aligned}
& \underset{\nearrow}{\searrow} \mathrm{Si}_{-} \mathrm{O}^{\bullet}+\mathrm{CH}_{3} \cdot \mathrm{CH}_{3} \longrightarrow \underset{-}{\succ} \mathrm{Si}-\mathrm{O}_{-} \mathrm{CH}_{3}{ }^{+}{ }^{\bullet} \mathrm{CH}_{3} \quad \mathrm{Eq}^{\cdot} 4 \\
& { }^{\circ} \mathrm{CH}_{3}+{ }^{\circ} \mathrm{CH}_{2} \cdot \mathrm{CH}_{3} \longrightarrow \mathrm{CH}_{3} \mathrm{CH}_{2} \mathrm{CH}_{3} \quad \mathrm{Eq} \cdot 5 \\
& 2^{\bullet} \mathrm{CH}_{2} \cdot \mathrm{CH}_{3} \longrightarrow \mathrm{CH}_{3} \mathrm{CH}_{2} \mathrm{CH}_{2} \mathrm{CH}_{3} \quad \mathrm{Eq} \cdot 6
\end{aligned}
$$

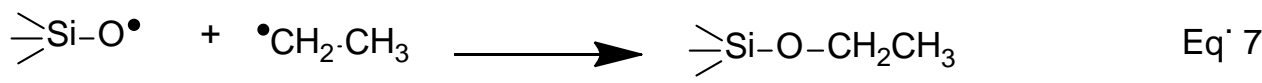

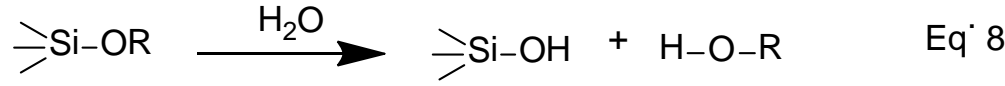

To gain insight into the products present in the solid phase that constitute over $90 \%$ of converted ethane, it was necessary to use doubly ${ }^{13} \mathrm{C}$-labeled ethane. It is important to comment at this point that the previous experiments were carried out with ethane of the highest available purity (99.999\%). In contrast, the purity of the available ${ }^{13} \mathrm{C}$-labeled ethane was lower (99.4\%). However, it is worth commenting that no significant differences were observed either in the ethane conversion or in the gas phase product distribution between these two ethane samples suggesting that possible impurities, and particularly possible traces of ethylene, are not playing a significant role on the photochemical process. While combustion chemical analysis of the solid serves to determine mass balances and the percentage of ethane-derived products adsorbed on the solid, their structure could be firmly determined by solid state ${ }^{13} \mathrm{C}$ NMR spectroscopy. Figure 1 shows the corresponding MAS ${ }^{13} \mathrm{C}$ NMR spectrum recorded for the commercial Beta zeolite after deep UV photolysis in the presence of 
ethane and $\mathrm{N}_{2}$. As it can been seen there, the major peaks correspond to adsorbed ethanol, methanol, butane and hexane. While the formation of ethanol and butane can be rationalized by radical coupling as indicated in Eqs. 3, 6, 7 and 8, formation of methanol requires the homolytic $\mathrm{C}-\mathrm{C}$ bond breaking with the formation of methoxysilane that will undergo hydrolysis to methanol (Eqs. 4 and 8 ). Hexane will arise from the coupling of ethyl and n-butyl radicals, the latter deriving from a secondary process from butane as starting material.

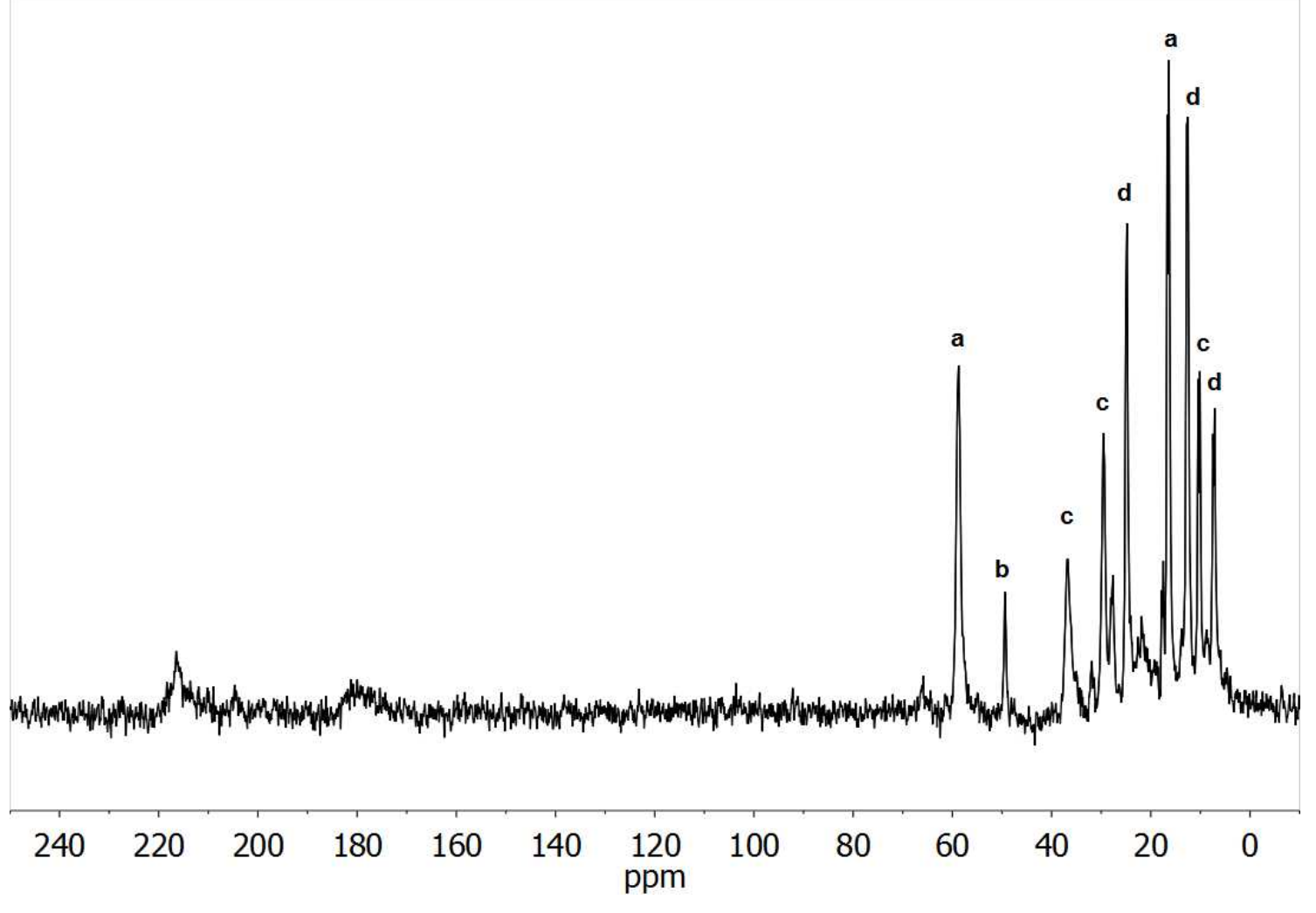

Figure 1: Solid-state MAS ${ }^{13} \mathrm{C}$ NMR spectrum recorded for commercial Beta zeolite after photolysis in the presence of ethane. Photolysis conditions: $185 \mathrm{~nm}$ irradiation at room temperature of a mixture of ethane (25\%) and $\mathrm{N}_{2}(75 \%)$ for $1 \mathrm{~h}$. The peaks labelled from a to $d$ have been assigned to ethanol, methanol, hexane and butane, respectively. 
The mechanistically relevant point is the observation of C2 and C1 alcohols that are most probably from by radical coupling of silanoxyl radicals with methyl and ethyl radicals followed by hydrolysis as indicated in Eqs 4, 7 and 8 .

When oxygen was present in the reaction mixture, a notable enhancement of the conversion, irrespective of the irradiation wavelength, was observed compared to the irradiations in where oxygen was absent (compare conversions in Tables 1 and 2). This fact can be understood considering the operation of a radical chain mechanism in which the initial trapping of alkyl radicals by oxygen leading to the formation of peroxyl radicals will generate subsequently another alkyl radical by hydrogen abstraction from ethane to the peroxyl radical (Eqs. 9 and 10). In this way the generation of a primary alkyl radical in the initiation stage can lead to the transformation of several ethane molecules during the propagation cycle.

$$
\begin{array}{ll}
\mathrm{CH}_{3}{ }^{-} \mathrm{CH}_{2}{ }^{-}+\mathrm{O}_{2} \longrightarrow \mathrm{CH}_{3}{ }^{-} \mathrm{CH}_{2} \mathrm{OO} & \mathrm{Eq} 9 \\
\mathrm{CH}_{3}{ }^{-} \mathrm{CH}_{2} \mathrm{OO}{ }^{-}+\mathrm{CH}_{3}{ }^{-} \mathrm{CH}_{3} \longrightarrow \mathrm{CH}_{3}{ }^{-} \mathrm{CH}_{2}{ }^{-} \mathrm{OOH}+\mathrm{CH}_{3}{ }^{-} \mathrm{CH}_{2}{ }^{-} & \mathrm{Eq} \cdot 10
\end{array}
$$

Besides conversion increase, the most relevant difference produced by the presence of oxygen concerns the product distribution and particularly the presence together with methanol and ethanol of other $\mathrm{C} 2$ and $\mathrm{C} 1$ oxygenates in detriment of the formation of propane and butane. Figure 2 shows the solid state ${ }^{13} \mathrm{C}$ NMR spectrum recorded for the commercial Beta zeolite after deep UV photolysis in contact with an atmosphere containing ethane and oxygen. For the sake of clarity, Figure 2 has labelled the most relevant peaks. The formation of acetaldehyde and acetic acid can be understood by the transformation of the ethyl peroxyl radical and subsequent 
oxidation. Formaldehyde and formic acid derived of methyl peroxyl radicals are also detected.

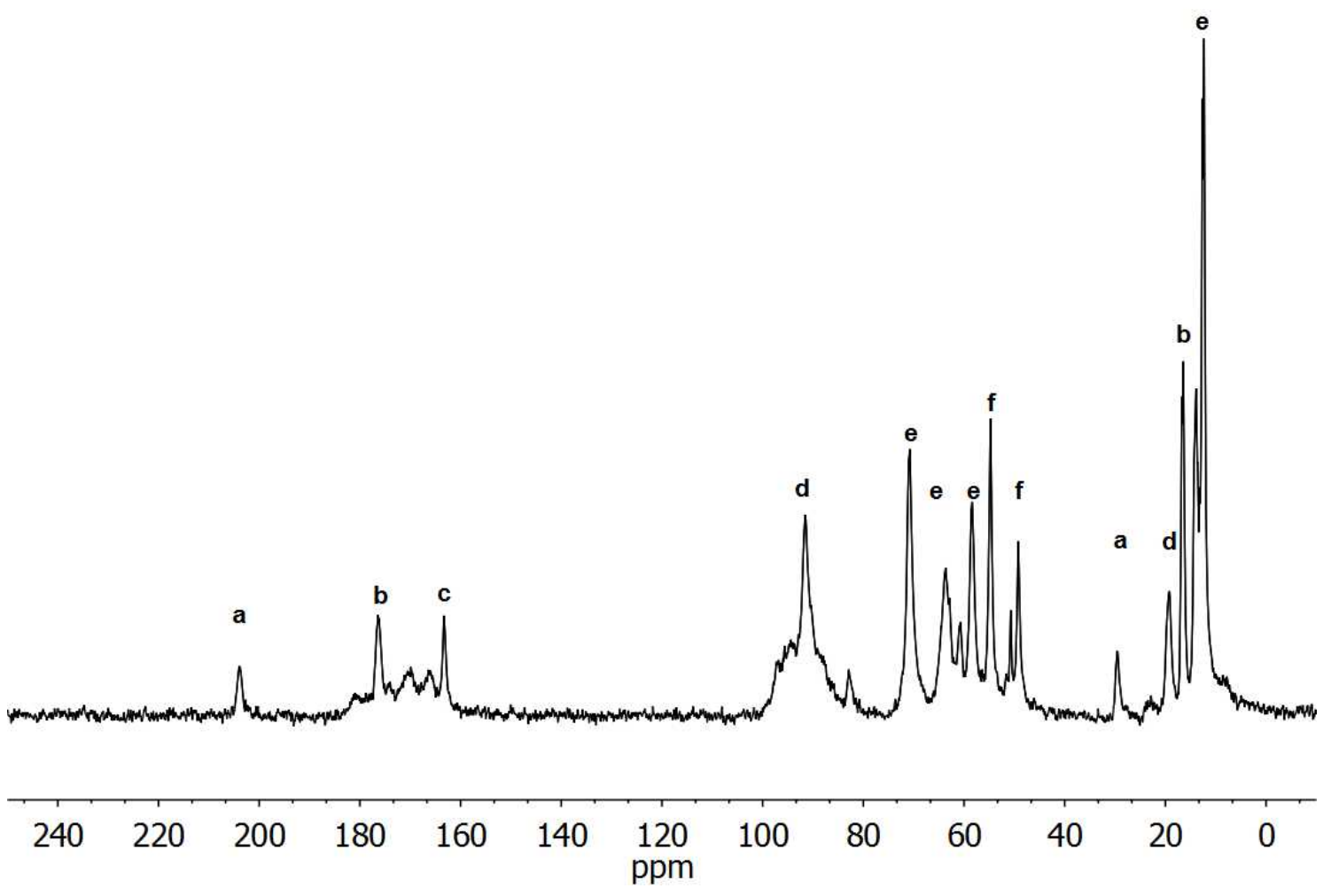

Figure 2: Solid-state MAS ${ }^{13} \mathrm{C}$ NMR spectrum recorded for commercial Beta zeolite after photolysis in the presence of ethane. Photolysis conditions: $185 \mathrm{~nm}$ irradiation at room temperature of a mixture of 70,18 and $12 \%$ of nitrogen, ethane and oxygen, respectively. The peaks labelled from a to $d$ assigned to acetaldehyde, acid acetic, formic acid, ethanol and methanol respectively.

In order to demonstrate that the polar products adsorbed onto the zeolite can be recovered by extraction, after $185 \mathrm{~nm}$ photolysis of ethane in the presence of zeolite Beta we proceeded to solid-liquid extraction of the solid using $\mathrm{D}_{2} \mathrm{O}$ and recorded the ${ }^{1} \mathrm{H}$ and ${ }^{13} \mathrm{C}$ NMR spectra of the $\mathrm{D}_{2} \mathrm{O}$ extract that also allows quantitative 
estimation of the product distribution. However, we notice that this extraction is not suitable for analysis of the light hydrocarbons formed in the process and is biased towards extraction of water soluble products. This lack of water solubility will be particularly problematic in the case of the photolysis in the absence of oxygen where a large percentage of hydrocarbons are formed, but however will be suitable for analysis of the photolysis under oxygen where all the products are water soluble and not volatile. As an example, Figure 3 shows the liquid ${ }^{13} \mathrm{C}$ NMR spectrum of the solid extract for the irradiation in the presence of oxygen. Based on these considerations and the similarity between the solid spectra of the zeolite Beta and the liquid spectra of the extract under oxygen, we have estimated the product distribution using NMR data of the solid. This avoids the problem of the insolubility of alkanes in water that should be particularly important for the photolysis in the absence of oxygen. The results are shown in Tables 3 and 4.

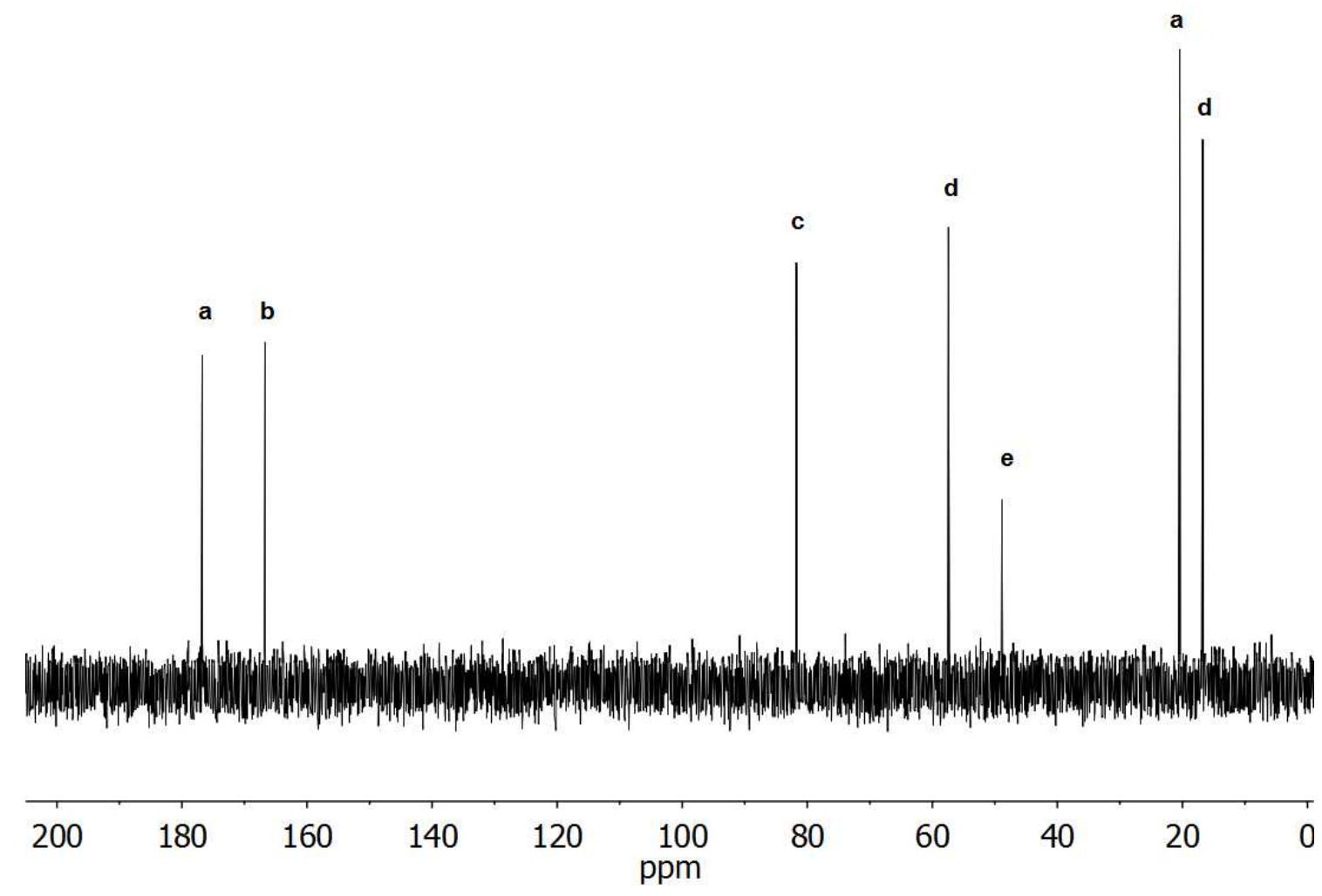


Figure 3. Liquid-phase ${ }^{13} \mathrm{C} N M R$ spectrum in $\mathrm{D}_{2} \mathrm{O}$ of the resulting liquor after extracting the zeolite Beta that has been previously submitted to photolysis in the presence of ethane and oxygen. Photolysis conditions: $1 \mathrm{~h}, 185 \mathrm{~nm}$ irradiation at room temperature of a mixture of 70,18 and $12 \%$ of nitrogen, ethane and oxygen, respectively. The peaks labelled from a to e can be assigned to acid acetic, formic acid, methanediol, ethanol and methanol, respectively.

Table 3. Conversion and product distribution determined for the room-temperature, deep UV photolysis of ethane on commercial Beta zeolite in the absence of oxygen, estimated based on the solid-state 13C NMR spectra. The initial composition of the gas phase was 82 and $18 \%$ of nitrogen and ethane, respectively, after $1 \mathrm{~h}$ irradiation at 185 $\mathrm{nm}$.

\begin{tabular}{|c|c|c|}
\hline \multicolumn{2}{|c|}{ Total conversion (\%) } & 4.5 \\
\hline \multicolumn{2}{|c|}{ Gas conversion (\%) } & 0.2 \\
\hline \multicolumn{2}{|c|}{ Solid conversion(\%) } & 4.3 \\
\hline \multicolumn{2}{|c|}{ Mass balance (\%) } & 96 \\
\hline \multirow{4}{*}{$\begin{array}{l}\text { Selectivity to the } \\
\text { porducts in the solid } \\
\text { phase }\end{array}$} & Ethanol & 31.6 \\
\hline & Methanol & 2.1 \\
\hline & Hexane & 26.7 \\
\hline & Butane & 39.6 \\
\hline
\end{tabular}

Table 2. Conversion and product distribution determined for the room-temperature deep UV photolysis of ethane on commercial Beta zeolite in the presence of oxygen, based on the solid state ${ }^{13} \mathrm{C}$ NMR spectra. The initial composition of the gas phase was 70,18 and $12 \%$ of nitrogen, ethane and oxygen, respectively, after $1 \mathrm{~h}$ of irradiation at $185 \mathrm{~nm}$

\begin{tabular}{|c|c|}
\hline Total conversion (\%) & 13.9 \\
\hline Gas conversion (\%) & 0.4 \\
\hline Solid conversion(\%) & 13.5 \\
\hline
\end{tabular}




\begin{tabular}{|c|c|c|}
\hline \multicolumn{2}{|c|}{ Mass balance (\%) } & 93 \\
\hline \multirow{4}{*}{$\begin{array}{c}\text { Selectivity to the } \\
\text { porducts in the solid } \\
\text { phase }\end{array}$} & Acetaldehyde & 3,2 \\
\cline { 2 - 3 } & Acid acetic & 14,1 \\
\cline { 2 - 3 } & Formic acid & 3,2 \\
\cline { 2 - 3 } & methanediol & 17,8 \\
\cline { 2 - 3 } & Ethanol & 47,7 \\
\cline { 2 - 3 } & methanol & 14 \\
\hline
\end{tabular}

To demonstrate the general scope of our approach based on the deep UV irradiation of the silanols to activate ethane at room temperature, we also proceeded to expand the results obtained with the commercial Beta zeolite to other silicas with the aim to assess which is the influence of the nature of the solid on the total conversion of ethane and the corresponding product distribution. The solids selected in the present study were an amorphous, non-porous, large surface area silica (Aerosil 200) as well as medium (ZSM5) and large pore monodirectional zeolite (Mordenite). Our study also includes two mesoporous silicas having MCM-41 structure but differing on the percentage of framework aluminum present in the structure. The results obtained employing these solids are shows in Table 5.

Table 5. Activity data and product distribution observed after $60 \mathrm{~min}$ for the room-temperature $185 \mathrm{~nm}$ photolysis of ethane on different zeolites in the presence of nitrogen. The composition of the gas phase was and 70, 18 and $12 \%$ of nitrogen, ${ }^{13} \mathrm{C}$-labelled ethane and oxygen, respectively 


\begin{tabular}{|c|c|c|c|c|c|}
\hline Catalyst & Aerosil 200 & H-ZMS5 & $\mathrm{NH}_{4}$-Mord & $\begin{array}{c}\text { MCM41 } \\
\text { (Si/Al } \infty)\end{array}$ & $\begin{array}{c}\text { MCM41 } \\
\text { (Si/Al 13) }\end{array}$ \\
\hline Total conversion $^{\text {a }}$ & 2.2 & 10.6 & 8.7 & 11.5 & 12.2 \\
\hline $\begin{array}{c}\text { Percentage of the total } \\
\text { conversion remaining } \\
\text { on the solid }\end{array}$ & 72.7 & 94.3 & 93.1 & 94.8 & 95.1 \\
\hline \multicolumn{5}{|c|}{ Products observed in the gas phase } \\
\hline Hydrogen & 5.8 & 8.6 & 6.2 & 7.0 & 6.2 \\
\hline CO $_{2}$ & 75.3 & 66.2 & 73.4 & 86.3 & 76.3 \\
\hline CO & 13.6 & 19.6 & 15.4 & $--{ }^{b}$ & 12.1 \\
\hline Methane & 5.3 & 5.6 & 5.1 & 6.7 & 5.3 \\
\hline
\end{tabular}

a) Mass balances over $95 \%$.

b) Below the detection limit.

As it can been seen in Table 5, ethane conversion after $1 \mathrm{~h}$ irradiation was similar in most of the samples except for Aerosil 200 that was significantly lower. We interpret this data considering that the presence of micropores providing a confined space, promotes ethane conversion. In addition of enhanced conversion, micro-/meso-porous solids also retain most of the converted ethane on the solid phase. These two facts, higher conversion retained on the solid surface, are also in agreement with the previous reported behavior observed for methane activation ${ }^{16,17}$.

Concerning the product distribution, although qualitatively the same compounds as those observed in the case of commercial Beta zeolite were also detected for the other zeolites, quantitatively some differences were detected in the percentage of each compound. To illustrate these variations Figure 4 compares the solid state, magic angle spinning ${ }^{13} \mathrm{C}$ NMR spectra recorded for MCM41 (Si/Al $\infty$ ) and Al- MCM41. 


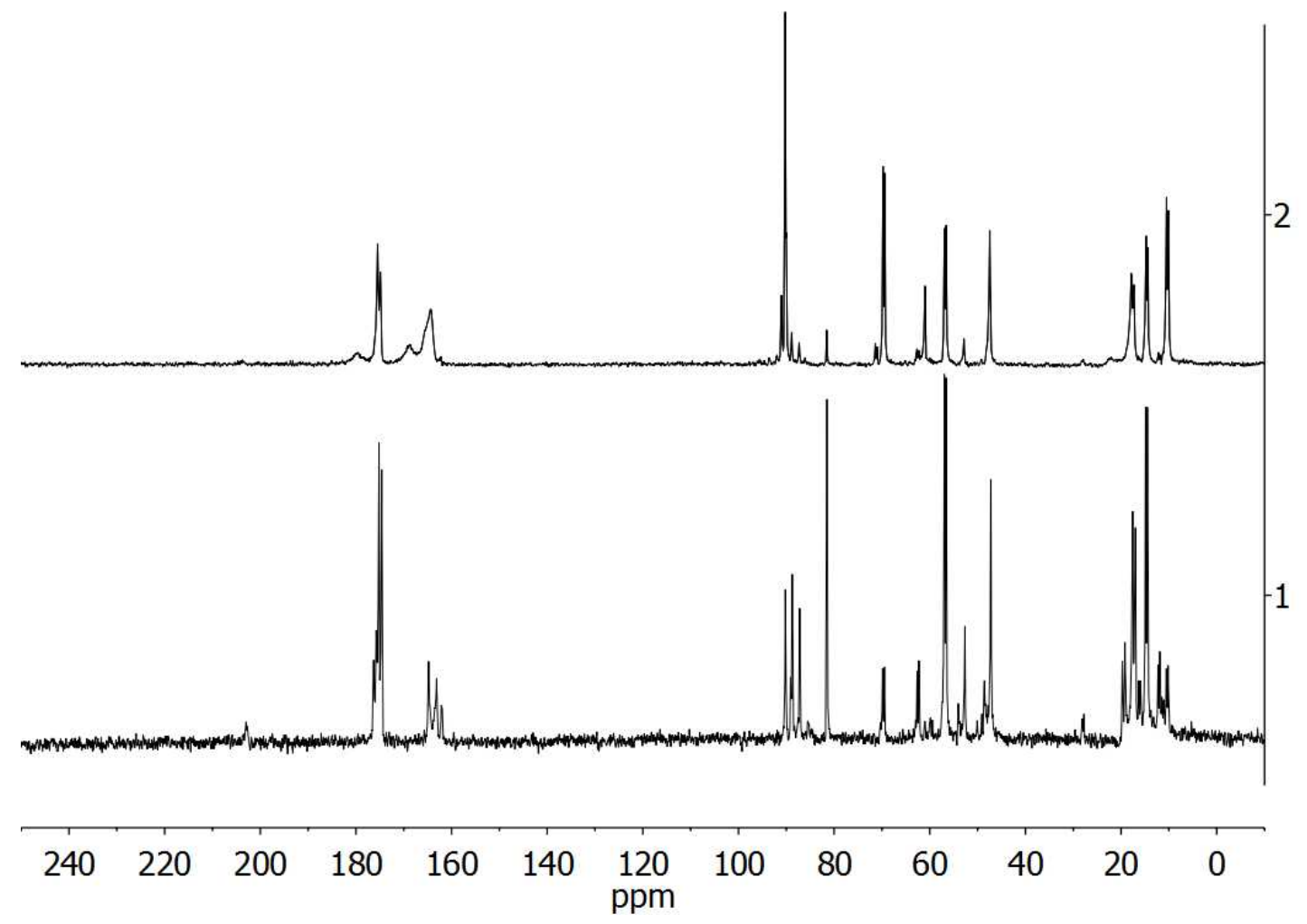

Figure 5. Solid-state MAS ${ }^{13} \mathrm{C}$ NMR spectra recorded for MCM41 (Si/Al $\left.\infty\right)$ (1) and MCM41 (Si/Al 13) (2) after $60 \mathrm{~min}$ for the room-temperature $185 \mathrm{~nm}$ photolysis of ethane. Photolysis conditions: $185 \mathrm{~nm}$ irradiation at room temperature of a mixture of 70,18 and $12 \%$ of nitrogen, ethane and oxygen, respectively.

As a general conclusion of Table 5, it can be said that MCM41 (Si/Al 13) is the most efficient material for the photocatalytic activation of ethane reaching the highest conversion and percentage of adsorbed material with a relatively simple product distribution.

To estimate the feasibility of the photocatalytic ethane activation by deep UV photolysis, we determined the energy consumption per mole of converted ethane based on the electrical power of the $185 \mathrm{~nm}$ lamp, the irradiation time, and the 
conversion achieved for this time. It was estimated that for a conversion of $6.0 \%$ reached in $5 \mathrm{~min}$, a $2.0 \mathrm{Gcal}$ per mol of ethane converted will be consumed. This value compares favorably with that previously estimate by us for methane and is about 8 times less than that corresponding for steam reforming of methane that is considered around $15.96 \mathrm{Gcalxmol}^{-1}{ }^{19-21}$. When taking these prelimary numbers into consideration, it is worth to remind that the energy consumption is strongly related to the process. The above commented results refer to a batch-wise process in which the products remain adsorbed in the solid. At larger scale it can be envision that the process should operate in a cyclic way comprising several steps including photolysis, product extraction and reactivation.

In summary in the present work we report that $185 \mathrm{~nm}$ irradiation of solid surfaces are able to promote the transformation of ethane into ethanol, light alkenes and $\mathrm{C} 1$ and $\mathrm{C} 2$ oxygenates. The presence of oxygen increases conversion and quenches the formations of alkanes. Although similar behavior was observed for all the silicas studied, mesoporous MCM41 (Si/Al 13) silica was found the most efficient one, probably due to the presence of a large population of silanol groups. The energy consumption for the catalytic process is about 3.6 times slower than that previously found activation of methane following an analogous treatment.

\section{Experimental section.}

Ethane and materials. The purity of the non-labelled ethane sample used in the present study for mass balances and gas phase analyses was $99.999 \%$ purity. The major impurity was nitrogen and the percentage of other hydrocarbons is below 
$0.0020 \%$. The purity of the doubly ${ }^{13} \mathrm{C}$-labelled ethane using for the NMR experiments was $99.4 \%$ having as main impurities air, $\mathrm{CO}_{2}$, and $\mathrm{CO}$. The content of other hydrocarbons different from ethane in the ${ }^{13} \mathrm{C}$-labeled sample is $0.4 \%$.

Aerosil 200 (Degusa), HZSM-5, Mordenite Beta zeolite and the others materials used in this work were either commercial samples (Beta zeolite VALFOR CP 811B-5, HZSM-5 Zeolyst CBV, Si/Al, from PQ Corporation) or were synthesised following the reported procedures (MCM41 and Al-MCM-41) ${ }^{22}$. Briefly, the MCM-41 sample was synthesized from Aerosil-200 as silica source, tetramethylammonium hydroxide (TMAOH, Aldrich), and hexadecyltrimethylammonium bromide (CTABr, Aldrich) as the surfactant template, following the procedure reported in ref. ${ }^{23}$. Thus, a gel of the following molar composition, $\mathrm{SiO}_{2}: 0.26 \mathrm{CTABr}: 0.40 \mathrm{TMAOH}: 29 \mathrm{H}_{2} \mathrm{O}$ was loaded in Teflon-lined stainless-steel autoclaves and heated in static at $408 \mathrm{~K}$ for $24 \mathrm{~h}$. The resulting solid was washed with distillate water and dried at $333 \mathrm{~K}$ overnight. Finally, the organic template was removed by calcination at $813 \mathrm{~K}$ in flowing $\mathrm{N}_{2}$ for $1 \mathrm{~h}$ and then with air at the same temperature for $5 \mathrm{~h}$, yielding the MCM-41 material.

Deep UV photolysis.

The $165 \mathrm{~nm}$ photo activation of ethane by irradiation of solid surfaces was performed by preparing compressed wafers $(2 \mathrm{~cm}$ diameter) of the corresponding powdered material. These wafers were placed in a chamber of $116 \mathrm{ml}$ capacity that was evacuated under vacuum and refilled with ethane and nitrogen (as internal standard) or ethane and air. 
The $185 \mathrm{~nm}$ photo activation of ethane was carried out using powdered samples that have previously pelletized for a size between 46 to 74 mesh and the powder was uniformly spread in the photoreaction covering a surface of $4 \times 13 \mathrm{~cm}^{2}$.

Figures 5 and 6 show the irradiance spectra of the lamps used. The course of the reaction was followed by analysis of the gas phase and the organic compounds adsorbed in the solid. Reproducibility of the experiments was checked by performing independent experiments in quadruplicate, whereby consistent results were obtained. The gas products were analyzed using a Rapid Refinery Gas Analiser from Bruker that consists in a three channel GC. The first channel analyses $\mathrm{H}_{2}$ using a micro packet HayeSep $Q$ and Molsieve $5 A$ column with Ar as carrier gas and TCD detector. The second channel analyses $\mathrm{CO}, \mathrm{CO}_{2}, \mathrm{~N}_{2}$, and $\mathrm{O}_{2}$ with a combination of micropacket Haysep Q, H-N and Molsieve $13 X$ columns using He as carrier gas and a TCD detector. The third channel analyses hydrocarbons from $\mathrm{C}_{1}$ to $\mathrm{C}_{5}$ in an $\mathrm{Al}_{2} \mathrm{O}_{3}$ plot column with $\mathrm{He}$ as carrier gas and a FID detector. The mass balance of each experiment was determined by adding the moles of the products in the gas phase to the moles of ethane converted in the solid. Quantification of the moles of the products in the gas phase was carried out considering that $\mathrm{N}_{2}$ remains constant during the experiment and using this gas as standard. The response factor of the products with respect to $\mathrm{N}_{2}$ was determined by independent calibrations. Quantification of the ethane converted in the solid phase was carried out by determining the carbon content by combustion chemical analysis and considering that the origin of all the carbon contained in the solid derived from ethane. Estimation of the product distribution in the solid phase was carried out based on the area of the peaks in solid-state ${ }^{13} \mathrm{C}$ NMR spectra. 
Extraction of the zeolite Beta after irradiation in the absence and presence of oxygen was carried out in an autoclave $(100 \mathrm{ml})$ using $20 \mathrm{ml}$ of $\mathrm{D}_{2} \mathrm{O}$. The solid and the liquid were placed inside the autoclave that was heated under stirring at $130{ }^{\circ} \mathrm{C}$ for $13 \mathrm{~h}$. After this time the solid was filtered and the liquid was submitted to NMR spectroscopy.

The energy consumption per mol of ethane converted was estimated taking into account the nominal power of the $185 \mathrm{~nm}$ lamp (4 W) and multiplying this number by $0.083 \mathrm{~h}$ time and dividing by the percentage of the initial mols of methane converted according to Equation 9.

Energy consumption $\left(\frac{\text { Gcal }}{\mathrm{mol}}\right)=\frac{4 \times \text { time } \times 859.845}{\delta \times 100}$

$\delta=$ percentage of initial moles of methane converted

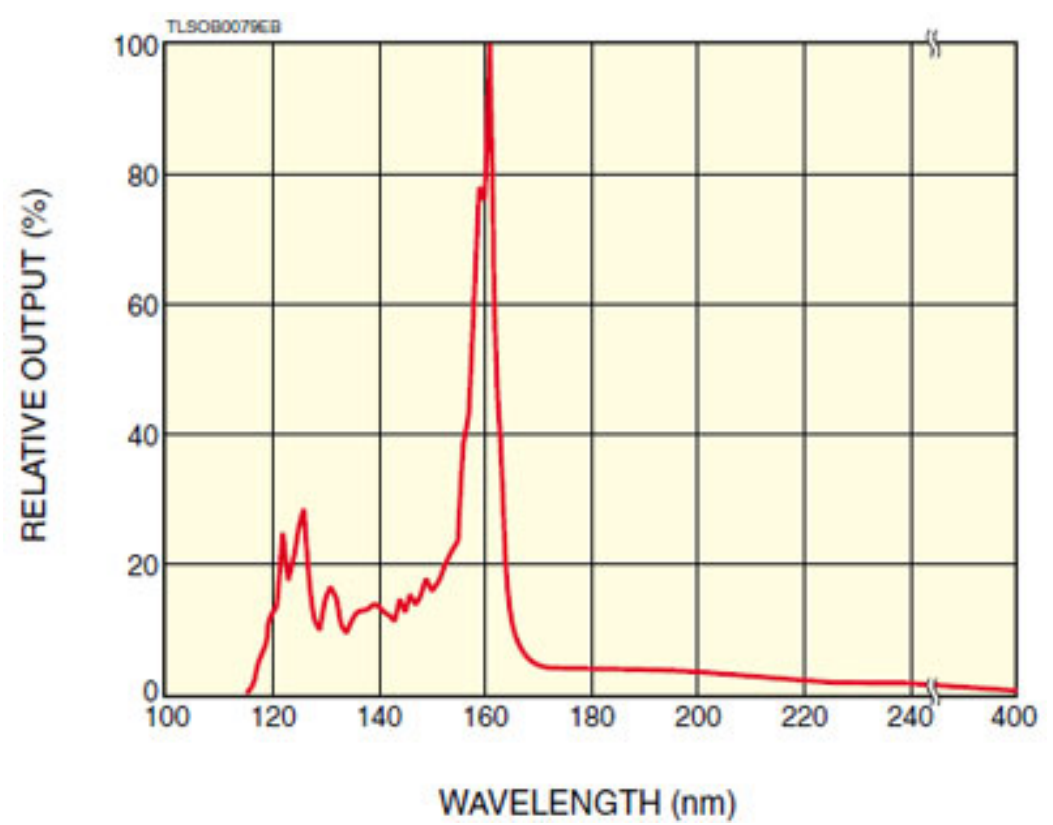

Figure 5. Emission spectrum of the deuterium lamp. 


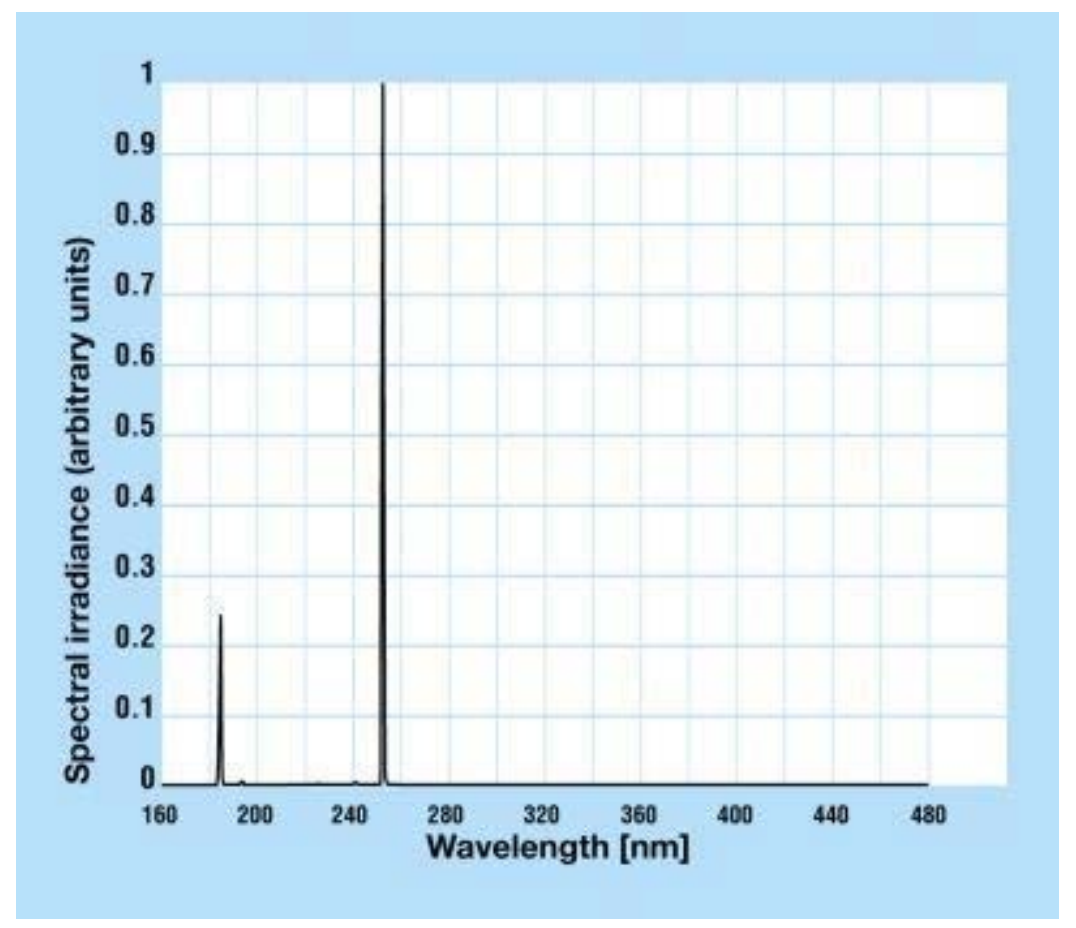

Figure 6. Emission spectrum of the In-Hg lamp.

\section{Acknowledgements.}

We would like to express our most sincere gratituted to Prof. J.-M-Herrmann that during all his career has been a guide and a reference for us in the field of photocatalysis. Financial support by the Spanish MICINN (Consolider Ingenio MULTICAT and CTQ2012-32315) is gratefully acknowledged.

References.

(1) Crabtree, R. H. Chemical Reviews 1995, 95, 987-1007.

(2) Fierro, J. L. G. Catalysis Letters 1993, 22, 67-91.

(3) Labinger, J. A.; Bercaw, J. E. Nature 2002, 417, 507-514.

(4) Schwarz, H. Angewandte Chemie-International Edition in English 1991, 30, 820821.

(5) Lunsford, J. H. Catalysis Today 2000, 63, 165-174.

(6) Amenomiya, Y.; Birss, V. I.; Goledzinowski, M.; Galuszka, J.; Sanger, A. R. Catalysis Reviews-Science and Engineering 1990, 32, 163-227. 
(7) Keller, G. E.; Bhasin, M. M. Journal of Catalysis 1982, 73, 9-19.

(8) Lee, J. S.; Oyama, S. T. Catalysis Reviews-Science and Engineering 1988, 30, $249-280$.

(9) Guisnet, M.; Gnep, N. S.; Alario, F. Applied Catalysis a-General 1992, 89, 1-30.

(10) Ismagilov, Z. R.; Matus, E. V.; Tsikoza, L. T. Energy \& Environmental Science 2008, 1, 526-541.

(11) Xu, Y. D.; Lin, L. W. Applied Catalysis a-General 1999, 188, 53-67.

(12) Yoshizawa, K.; Shiota, Y.; Yumura, T.; Yamabe, T. Journal of Physical Chemistry B 2000, 104, 734-740.

(13) Basch, H.; Mogi, K.; Musaev, D. G.; Morokuma, K. Journal of the American Chemical Society 1999, 121, 7249-7256.

(14) Gesser, H. D.; Hunter, N. R.; Prakash, C. B. Chemical Reviews 1985, 85, 235-244.

(15) Otsuka, K.; Wang, Y. Applied Catalysis a-General 2001, 222, 145-161.

(16) Sastre, F.; Fornés, V.; Corma, A.; García, H. Chem. Eur. J. in press, 17.

(17) Sastre, F.; Fornés, V.; Corma, A.; García, H. J. Am. Chem. Soc. in press, 133.

(18) March, J. Advanced Organic Chemistry: Reactions, Mechanisms and Structures; 3rd ed.; McGraw Hill: New York, 1993.

(19) Hu, Y. H.; Ruckenstein, E. In Advances in Catalysis, Vol 48 2004; Vol. 48, p 297345.

(20) Rostrup-Nielsen, J. R.; Sehested, J.; Norskov, J. K. In Advances in Catalysis, Vol 47 2002; Vol. 47, p 65-139.

(21) Vanhook, J. P. Catalysis Reviews-Science and Engineering 1980, 21, 1-51.

(22) Atienzar, P.; Navarro, M.; Corma, A.; Garcia, H. ChemPhysChem 2009, 10, $252-$ 256.

(23) Corma, A.; V., F.; Navarro, M. T.; Pérez-Pariente, J. J. Catal. 1994, 148, 569-574. 